\title{
BMJ Open Occupational justice and social inclusion among people living with HIV and people with mental illness: a scoping review
}

\author{
Clement Nhunzvi (D , ${ }^{1}$ Lisa Langhaug, ${ }^{2}$ Edwin Mavindidze, ${ }^{3}$ Richard Harding (D) , ${ }^{4}$ \\ Roshan Galvaan ${ }^{5}$
}

To cite: Nhunzvi C,

Langhaug L, Mavindidze E, et al. Occupational justice and social inclusion among people living with HIV and people with mental illness: a scoping review. BMJ Open 2020;10:e036916. doi:10.1136/ bmjopen-2020-036916

- Prepublication history and additional material for this paper are available online. To view these files, please visit the journal online (http://dx.doi org/10.1136/bmjopen-2020036916).

Received 10 January 2020 Revised 31 May 2020 Accepted 02 June 2020

Check for updates

(C) Author(s) (or their employer(s)) 2020. Re-use permitted under CC BY. Published by BMJ.

For numbered affiliations see end of article.

Correspondence to

Clement Nhunzvi;

clemynhu@gmail.com

\section{ABSTRACT}

Objective To explore ways in which occupational justice and social inclusion are conceptualised, defined and operationalised in highly stigmatised and chronic conditions of mental illness and HIV.

Design This scoping review protocol followed Arksey and 0'Malley's (2005) Scoping Review Framework.

Data sources and eligibility The following databases were searched for the period January 1997 to January 2019: Medline via PubMed, Scopus, Academic Search Premier, Cumulative Index to Nursing and Allied Health Literature (CINAHL), Africa-Wide Information, Humanities International Complete, Web of Science, PsychInfo, SocINDEX and grey literature.

Eligible articles were primary studies, reviews or theoretical papers which conceptualised, defined and/or operationalised social inclusion or occupational justice in mental illness or HIV.

Study appraisal and synthesis We undertook a three-part article screening process. Screening and data extraction were undertaken independently by two researchers. Arksey's framework and thematic analysis informed the collation and synthesis of included papers.

Results From 3352 records, we reviewed 139 full articles and retained 27 for this scoping review. Definitions of social inclusion and occupational justice in the domains of mental illness and HIV were heterogeneous and lacked definitional clarity. The two concepts were conceptualised as either processes or personal experiences, with key features of community participation, respect for human rights and establishment and maintenance of healthy relationships. Conceptual commonalities between social inclusion and occupational justice were premised on social justice.

Conclusions To address lack of clarity, we propose further and concurrent exploration of these concepts, specifically with reference to persons with comorbid mental health disorders such as substance use disorders and HIV living in low-income countries. This should reflect contextual realities influencing community participation, respect for human rights and meaningful occupational participation. From this broadened understanding, quantitative measures should be applied to improve the standardisation of measurements for occupational justice and social inclusion in policy, research and practice.
Strengths and limitations of this study

- The methodology as provided by the scoping review design, facilitated comprehensive mapping of the literature, and presented a foundation for further exploration utilisation of the concepts to inform policy, research and practice.

-We used a rigorous strategy to explore research foci, definitions and utilisations of the concepts of social inclusion and occupational justice in mental illness and HIV.

- Data synthesis was limited to work published in English originally or with available Englishtranslated copies.

- We focused on mental illness, which is made up of several different conditions and could have introduced generalisation bias. However, most of the included studies were also not condition specific, fitting our primary aim for conceptual review.

- Focus was limited to conceptual and theoretical aspects of the concepts more than interventions and outcomes of interventions.

\section{INTRODUCTION}

The global burden of disease from HIV remains substantially high with approximately 37.9 million people living with HIV. ${ }^{1}$ However, in the last two decades, the world has seen a combination of a significantly decreased mortality and a small decrease in incidence leading to an increase in the number of people living with HIV from $8 \cdot 74$ million (1990) to $36 \cdot 9$ million $(2017){ }^{2}$ This increase in the number of people living with HIV and decreased mortality rates are largely a result of the scaling up of HIV treatments. ${ }^{13}$ However, what remains as a concern are persisting gaps in the treatment continuum towards the UNAIDS (The Joint United Nations Programme on HIV and AIDS) 90-90-90 target. Among those living with HIV who knew their status globally, $17 \%$ were still not on life-saving antiretroviral 
therapy (ART) UNAIDS Global AIDS update 2019. ${ }^{1}$ Moreover, only $53 \%$ of those on treatment were virally suppressed. ${ }^{13}$ One reason for these discrepancies, mainly seen in key populations, is the rising and ever complex relationship between mental illness and HIV. ${ }^{45}$ Secondary to both biological and psychosocial factors, people living with HIV are at an increased risk of experiencing poor mental health ${ }^{67}$ which negatively impacts on their healthseeking behaviours, adherence to antiretroviral treatments ${ }^{8}$ and quality of life. ${ }^{9}$ The prevalence of common mental disorders is also significantly higher among people living with HIV, irrespective of them being on ART, and is further impounded by stigma. ${ }^{10}$ There is also a known bidirectional relationship between HIV and mental health, worsened by associated health and social inequalities. This often leaves people with severe mental illnesses at an increased risk for HIV infection. ${ }^{11} 12$

Individuals with chronic and usually stigmatised conditions, such as mental illnesses, physical disabilities and HIV, face barriers to full participation in their communities. ${ }^{13}$ Poverty, lack of access to education, lack of suitable housing and unemployment are some of the social and economic barriers to accessing adequate and sustained healthcare faced by this group. ${ }^{14}$ These barriers may similarly be experienced by people who face discrimination based on their class, race or gender identity or sexuality and thus, when persons with mental illness also share these characteristics they may be severely stigmatised or discriminated against. ${ }^{1516}$

To sustain the aforementioned progress in the management of people with HIV and its comorbidities such as mental illness, there is a renewed call to take a community-led, equality and social justice approach ${ }^{3}{ }^{12}$ with concepts like occupational justice and social inclusion holding promise to inform this agenda. Occupational justice is an advanced form of social justice, concerned with equity and fairness for individuals, groups and communities access to resources and opportunities that supports their engagement in diverse, healthy and meaningful occupations. ${ }^{17}$ On the other hand, social inclusion entails multidimensional processes or states where prevailing contextual conditions enable full and active participation in all aspects of everyday life. ${ }^{19} 20$ This can include civic, social, economic and political activities, as well as participation in decision-making processes irrespective of personal characteristic differences. ${ }^{19} 20$

Social inclusion and occupational justice form aspects of social justice and are therefore relevant to direct research and practice as we address exclusions and injustices experienced by stigmatised groups ${ }^{21}$. Focus on these social justice outcomes ensures that health and social well-being are addressed beyond the clinical management of the disease. Health-related quality of life that includes social inclusion and occupational justice will be a holistic construct for promoting continuum of care and health and well-being beyond viral suppression in HIV. 2223 These concepts direct the health and social care communities to view individuals with mental illness and
HIV as being part of marginalised groups at risk of being deprived of respect, rights and opportunities to achieve optimal health-related quality of life.

Social inclusion and occupational justice are potentially key concepts that can inform the promotion of human rights-based, sustainable, person and community-centred interventions that promote recovery for persons with chronic and stigmatised conditions. ${ }^{245}$ In order to aid integration and operationalisation of occupational justice and social inclusion in practice, we need to understand how the concepts are conceptualised and applied in population groups affected by chronic and stigmatised conditions. Synthesised summaries of research evidence can inform primary research and implementation science, ${ }^{26}$ therefore we selected a scoping review design to help advance this field. ${ }^{27}$ This was a particularly appropriate method for this area due to the diverse disciplinary locations of the existing literature. ${ }^{28} 29$ This scoping review aimed to explore and appraise the definitions, current utilisation and relationships between the concepts of social inclusion and occupational justice in mental illness and HIV literature.

\section{METHODS}

This scoping review followed our published study protocol, ${ }^{27}$ developed using Arksey and O'Malley's Scoping Review framework,${ }^{29}$ as well as guidelines for scoping review protocols in occupational therapy. ${ }^{26}{ }^{30}$ In this paper, a scoping review is taken to be a form of knowledge synthesis that addresses an exploratory research question rather than the highly focused question in a systematic review. ${ }^{28}{ }^{29}$ For reporting, we followed the PRISMA extension for Scoping Reviews (PRISMA-ScR) Checklist. ${ }^{31}$

We followed an iterative process to develop and refine the research question. ${ }^{29}$ Based on the subject area terminology, literature and our understanding of current practice trends in managing conditions that are chronic, and stigmatised, we asked the following question:

How are occupational justice and social inclusion conceptualised, defined and operationalised, and how are these concepts related in the highly stigmatised chronic conditions of mental illness and HIV?

The objectives of our scoping review were

1. To identify articles that define or conceptualise occupational justice and social inclusion related to mental illness and/or HIV.

2. To describe how these are operationalised or utilised.

3. To identify and describe relationships between occupational justice and social inclusion.

4. To determine potential areas for further development, integration, and application of these concepts.

\section{Search strategy}

With the aid of a subject librarian, we identified appropriate databases using a journal indexing system. We 
Table 1 General search strategy

\begin{tabular}{ll}
\hline Key word & Alternative words \\
\hline Occupational therapy & Occupational rehabilitation \\
& AND \\
Mental illness & $\begin{array}{l}\text { Mental health OR Mental disorder OR } \\
\text { Psychiatric disability }\end{array}$ \\
& AND \\
Occupational justice & $\begin{array}{l}\text { Occupational injustice OR Occupational } \\
\text { marginalisation OR Occupational } \\
\text { alienation OR Occupational imbalance OR } \\
\text { Occupational deprivation }\end{array}$ \\
& AND \\
Social inclusion & $\begin{array}{l}\text { Social exclusion OR Social isolation OR } \\
\text { social integration }\end{array}$ \\
& AND \\
HIV & HIV OR HIV/AIDS OR HIV infection OR \\
\hline
\end{tabular}

searched 12 databases in January 2019: (1) PubMed, (2) Scopus, (3) Academic Search Premier, (4) the Cumulative Index to Nursing and Allied Health Literature (CINAHL), (5) Africa-Wide Information, (6) Humanities International Complete, (7) Web of Science, (8) PsychInfo, (9) SocINDEX, (10) Grey Literature Report, (11) Web of Science Conference Proceedings and (12) Open Grey. We used PubMed as the free platform for accessing articles indexed on Medline database. The selected databases captured a comprehensive sample of literature from a variety of disciplines including social work, psychiatry, nursing and occupational therapy.

The first and last authors (CN and RG) worked with the librarian, through an iterative process, to develop an inclusive list of search terms and applicable filtering methods including Boolean phrases and Medical Subject Headings (MeSH) terms for each database. ${ }^{27}$ We developed a general search strategy with primary search terms related to the primary concepts of occupational justice and social inclusion, while secondary search terms encompassed the broader terms of mental health, occupational therapy, mental illness, HIV and rehabilitation (table 1). For the purposes of search strategy development, we restricted our search to literature published between January 1997 and January 2019, a period which has seen the emergence and rapid growth in literature on occupational justice. ${ }^{32}$
We conducted a preliminary search on PubMed and this enabled refinement of our search strategy to maximise sensitivity and specificity. We adapted the PubMed search strategy (online supplementary appendix 1) accordingly for other databases.

\section{Study selection}

The first author $(\mathrm{CN})$ reviewed the titles identified in the search for eligibility. The aim was to identify articles that (1) indicated a research focus on mental illness, or HIV, or both and (2) titles that included the key terms of occupational justice, social inclusion or both. Article types included primary studies, reviews, opinion papers and other theoretical papers without primary data. Articles were not eliminated where there was uncertainty with the title until it was examined more in-depth by looking at the abstract. Two independent reviewers, the first and third authors $(\mathrm{CN}$ and EM), reviewed titles and abstracts of preliminarily selected articles using predetermined inclusion and exclusion criteria (table 2), detailed in our protocol. ${ }^{27}$ These same reviewers each further screened full-text articles to determine if they met the inclusion/exclusion criteria. At this stage, articles were included if their explicit focus was on social inclusion or occupational justice in mental illness and/or HIV; concepts were defined and reported some operationalisation of the two concepts. Discrepancies were resolved by consensus or by seeking adjudication from the second author (LL). The Cohen's $\kappa$ statistic to determine inter-rater agreement was calculated for the title and abstract review and the full article review stage, giving more than $90 \%$ agreement between reviewers with Cohen's $\kappa$ statistic of 0.78 and 0.83 respectively.

\section{Data extraction}

Guided by the study objectives, a common extraction table was designed, to extract standard bibliometric information study characteristic and main findings. The first five articles were reviewed by both the first and third authors, with the remaining articles divided between the two authors. We then checked for accuracy and completeness against each other's work. Discrepancies were resolved by revisiting the article, discussing and reaching consensus.

\section{Table 2 Inclusion and exclusion criteria for acceptable articles}

\section{Criteria for inclusion}

Minimum criteria required in the abstract:

- Explicit mention of mental illness, and/or HIV/AIDS.

- Explicit mention of either occupational justice and its varieties or social inclusion and its varieties. (varieties were informed by how articles with these terms were indexed in databases)

- Date range (January 1997 to January 2019).

- English language

- English translation of abstract and article available

\section{Criteria for exclusion}

- Used animal subjects. 


\section{Data synthesis}

Data were synthesised descriptively to give a structured summary of the dataset and to capture the characteristics of the studies included and the definitional range of social inclusion and occupational justice. Study grouping followed the publication trends over time and study designs used. Descriptive statistics were calculated using Microsoft Excel version 16.0 for frequencies. We used deductive thematic analysis to organise the extracted definitions and related concepts for occupational justice and social inclusion.

\section{Patient and public involvement}

Patient and public involvement representatives were not directly involved in the design of this scoping review protocol. However, experiences of the first author in working with adults afflicted with HIV and mental health disorders in Zimbabwe informed the need to explore issues faced by this population beyond biomedical care. We also built our research question from insights being generated in his doctoral studies exploring occupational perspectives on social inclusion among young adults dually afflicted with substance use disorders and HIV. Social inclusion speaks to life beyond medical management which was not being given sufficient attention and hence the need to conduct a scoping review.

\section{RESULTS}

\section{Retained studies' characteristics}

As described in figure 1 , we screened titles $(n=3352)$ and after reviewing $(n=139)$ full articles 27 were included in this scoping review. Of the $(n=27)$ sources included for final review, 23 were published between 2009 and 2018, with the majority $(n=6)$ of these published in 2012 (table 3). Most publications were by authors in the mental health field and from high-income countries, with $68 \%$ of the primary studies being conducted in Europe, ${ }^{33-45}$ and $9 \%$ in Australia. ${ }^{46} 47$ No primary studies were conducted in North America, Africa or Asia. More than a third $(n=10)$ of the studies utilised a qualitative research design, ${ }^{34-37} 40-4244464849$ five $(16 \%)$ utilised a quantitative research design 3338394547 and only one study utilised a mixed-methods design. ${ }^{43}$ Six $(19 \%)$ were review papers and the remainder $(n=5)$ were opinion, ${ }^{50}{ }^{51}$ lectureship, ${ }^{52}$ commentary $^{53}$ and theoretical analysis papers. ${ }^{54}$ The two concepts were predominantly explored around mental illness $(n=26)$ with significantly less focus on HIV $(n=1)$. The majority $(n=21)$ of the published research investigated social inclusion as it related to mental health conditions, and all the occupational justice papers were focused on mental illness. Only one paper was included which discussed social inclusion in relation to people living with HIV. ${ }^{55}$ We found no published literature that explored occupational justice and social inclusion in populations with comorbid mental illness and HIV.

\section{SOCIAL INCLUSION: CONCEPTS AND DEFINITIONS}

Social inclusion was defined with high variability, with only two studies using the same definition by defining social inclusion as a subjective sense of belonging and active citizenship that enhances social integration. ${ }^{40}$ Conceptualisations and definitions used ambiguous words such as 'community', 'participation' and 'integration' to define social inclusion. Some studies defined social inclusion in terms of paid work and participation in community events, ${ }^{38} 39$ others focused on social acceptance and absence of stigma, ${ }^{40424556}$ while still others saw it as a political discourse. ${ }^{41}$ Stain $e t a l^{77}$ tried to capture these varieties, and defined social inclusion as

the participation of a person in society, evidenced by an individual having the opportunities, resources and abilities to build and maintain relationships, engage in education and employment, and participate in community events and organisations. (p880)

Notable thematic areas emerged from the analysis of the definitions, namely community participation, human rights and social relations that enhances a sense of acceptance and belonging.

\section{Community participation}

The most prominent shared features of the definitions of social inclusion in mental illness and HIV research focused on it being a process and an experience centred on community participation. However, the terms 'community participation' and 'community' were used in many ways without clear descriptions. These varied interpretations of community participation included reference to people with HIV or mental illness were wide ranging and included individuals with opportunities to participate in key activities in their communities like paid employment $^{38394757}$; being integrated into the community ${ }^{374145}$; having a sense of belonging within the community ${ }^{33} 404251$; and exercising active citizenship. ${ }^{39558}$

\section{Human rights}

Social inclusion was also defined and conceptualised as a human rights issue, ${ }^{3946495658}$ even though community participation was the penultimate indicator for social inclusion. When discussing human rights, the authors highlighted an individual's right to access resources and opportunities for personal and community growth. Social inclusion was also conceptualised as the right to engage in productive occupations, with full access to work and/or educational activities within the community despite one's health concerns. ${ }^{58}$

\section{Social relations}

Social inclusion was further conceptualised and defined as a subjective experience, ${ }^{33} 4042434547$ where those who are socially included should experience positive relationships. While a number of authors 334042434547 talked about relationships as being a key component, this was not defined or discussed in depth. Instead it was emphasised that for social inclusion to be a reality, an individual should 


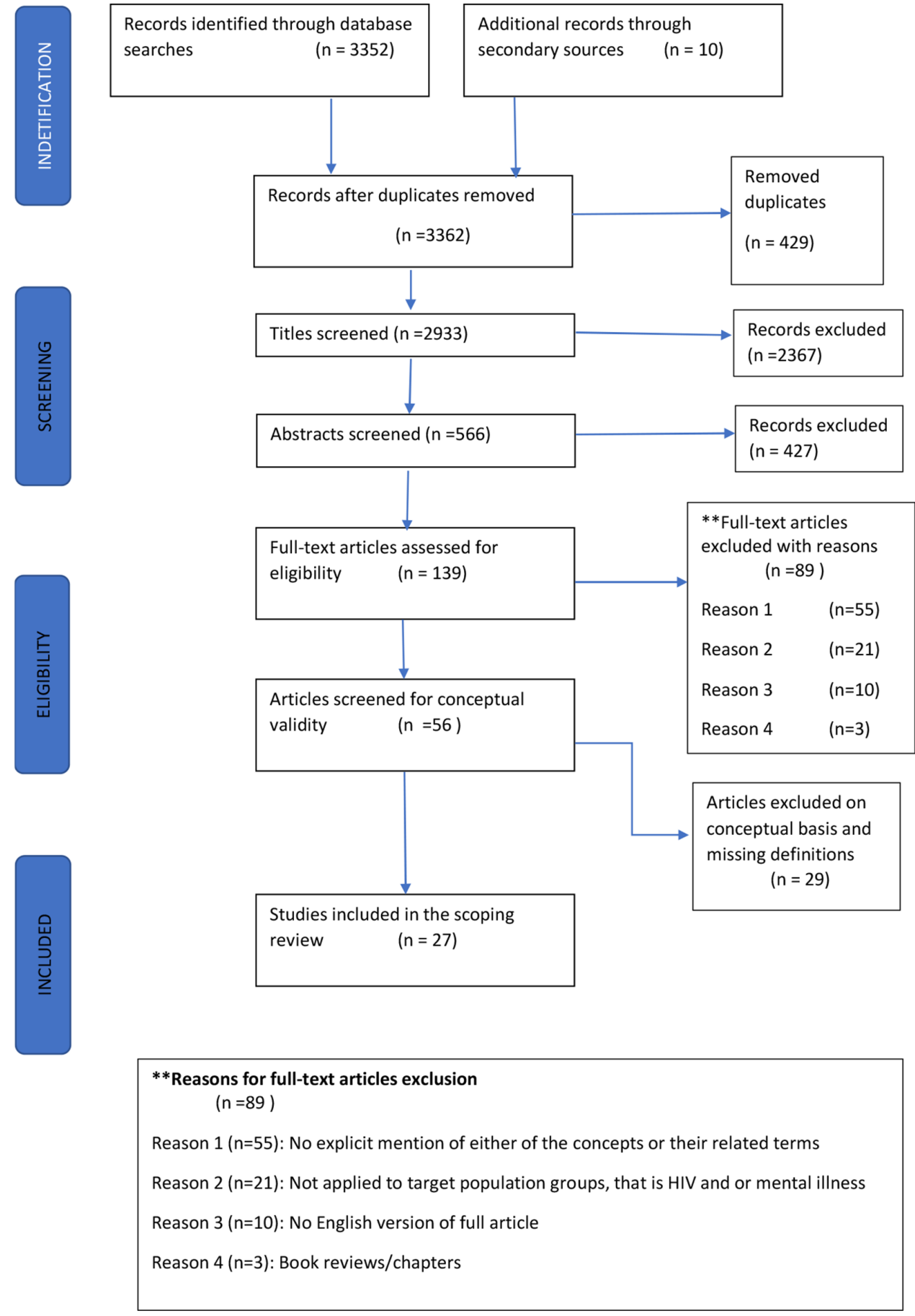

Figure 1 Scoping review flow diagram.

experience positive social relationships with their significant others, family, friends and acquaintances. 334042434547 Social inclusion was also conceptualised as experiencing social support and having positive support networks. ${ }^{45}$

\section{Diversity in definitions reflected in measurement tools}

The diversity in definitions and features was also present in the measurement tool used. Quantitative studies included one of the following social inclusion measures: (1) Social Inclusion Questionnaire, ${ }^{43}$ (2) Social Relationships Scale and Social Inclusion Scale, ${ }^{33}$ (3) Social Inclusion Interview Schedule ${ }^{45}$ and (4) Social Inclusion Questionnaire
User Experience. ${ }^{38}$ Social inclusion was also portrayed in some definitions as a subjective personal concept, where it is the individual with mental illness or person living with HIV, who subjectively experiences inclusion and should have a choice on what determines their experience of such inclusion. ${ }^{3440424451}$ It is their perception of the quality of their relationships, their acceptability to others, and how integrated they are, which was emphasised.

In summary, social inclusion was conceptualised as processes and experiences of empowered and equitable community participation for all, in which there is respect 


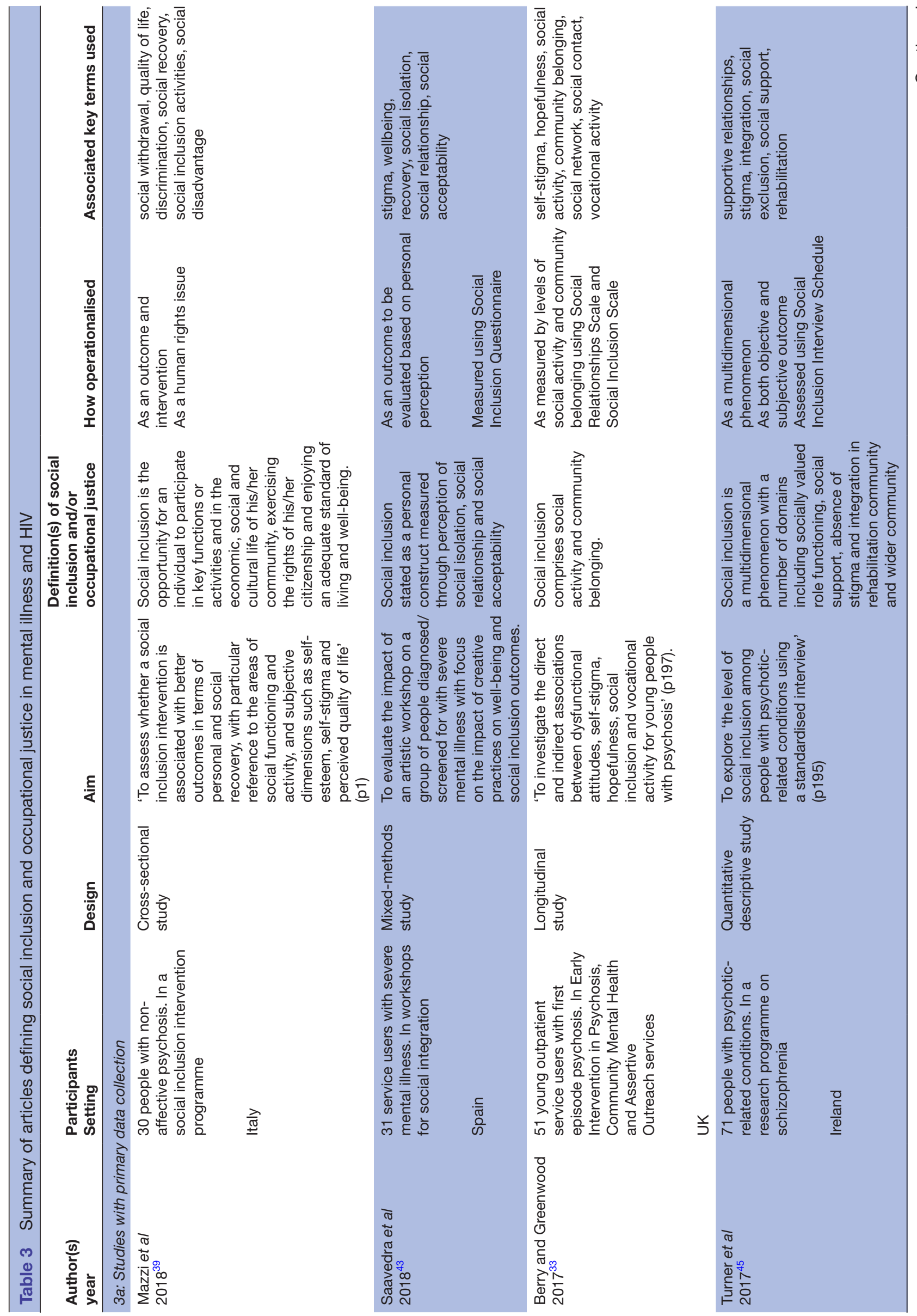




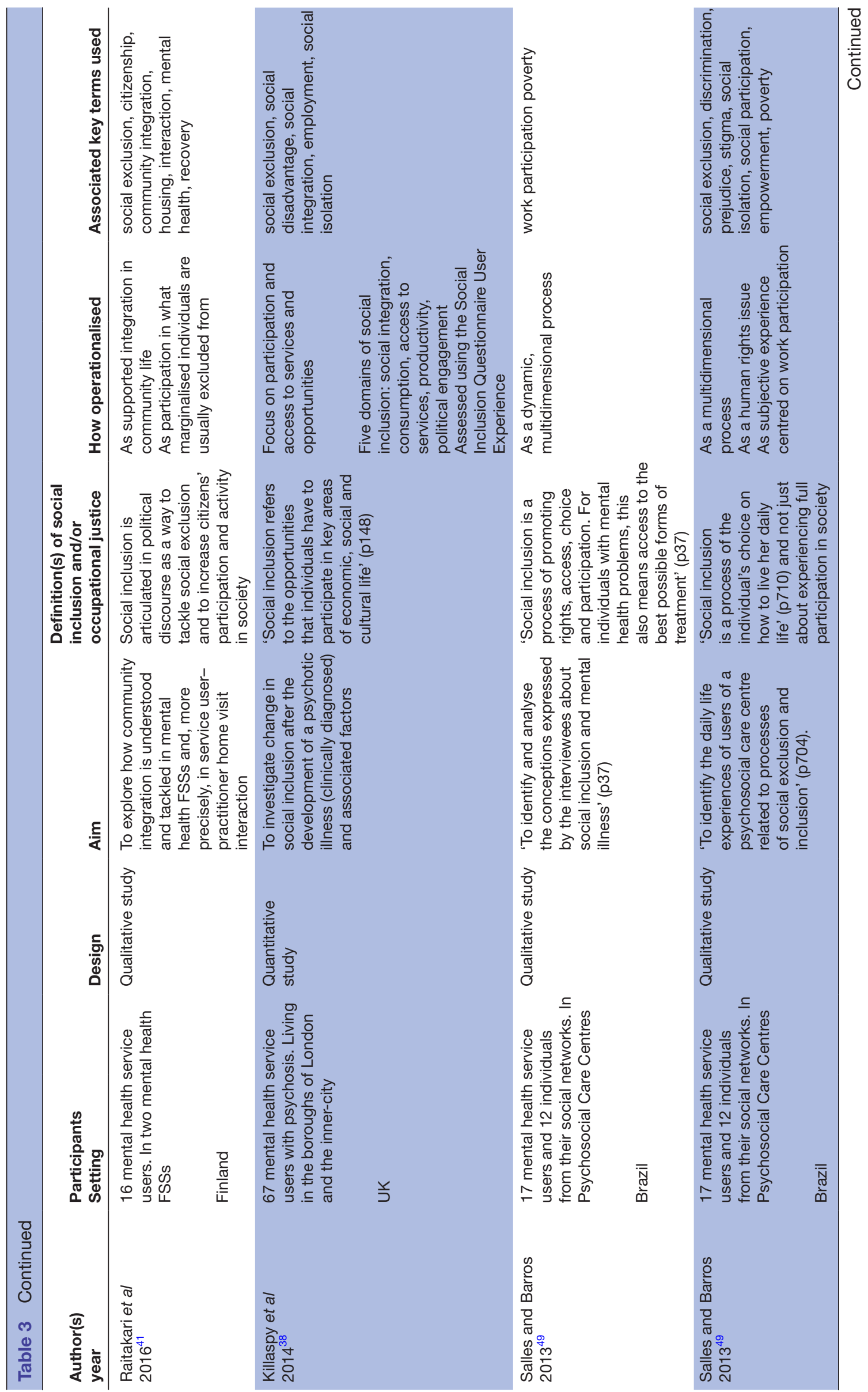




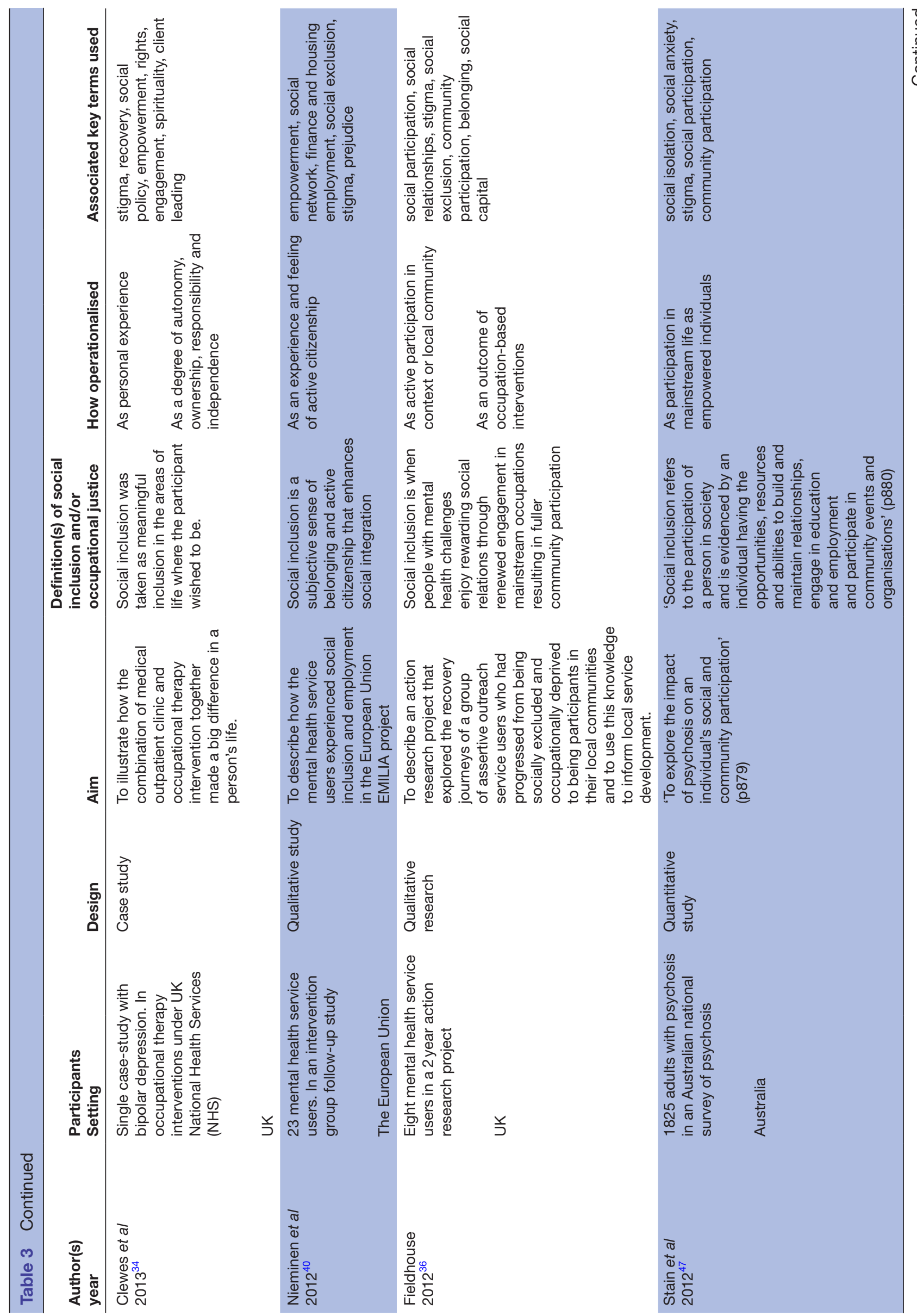




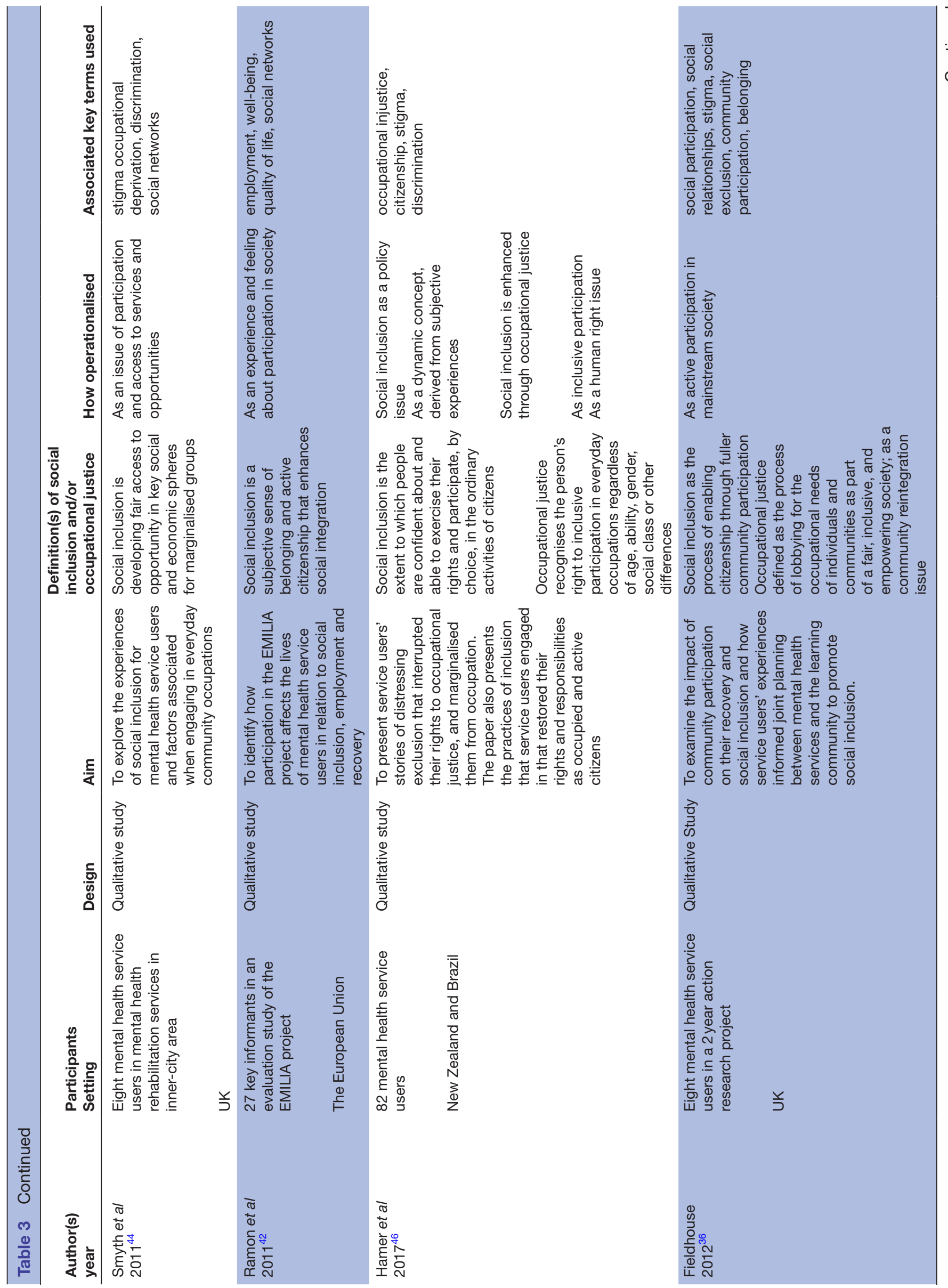




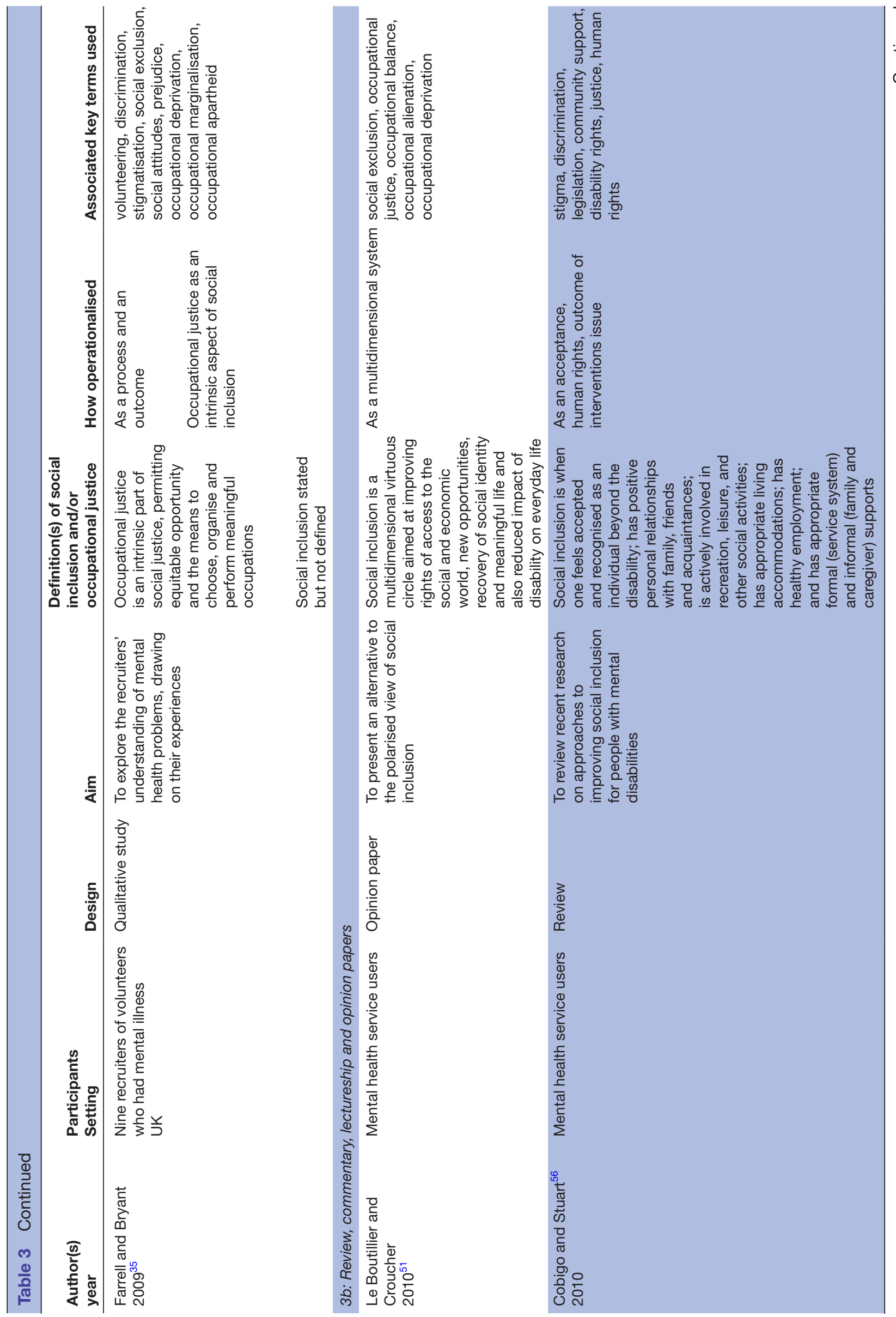




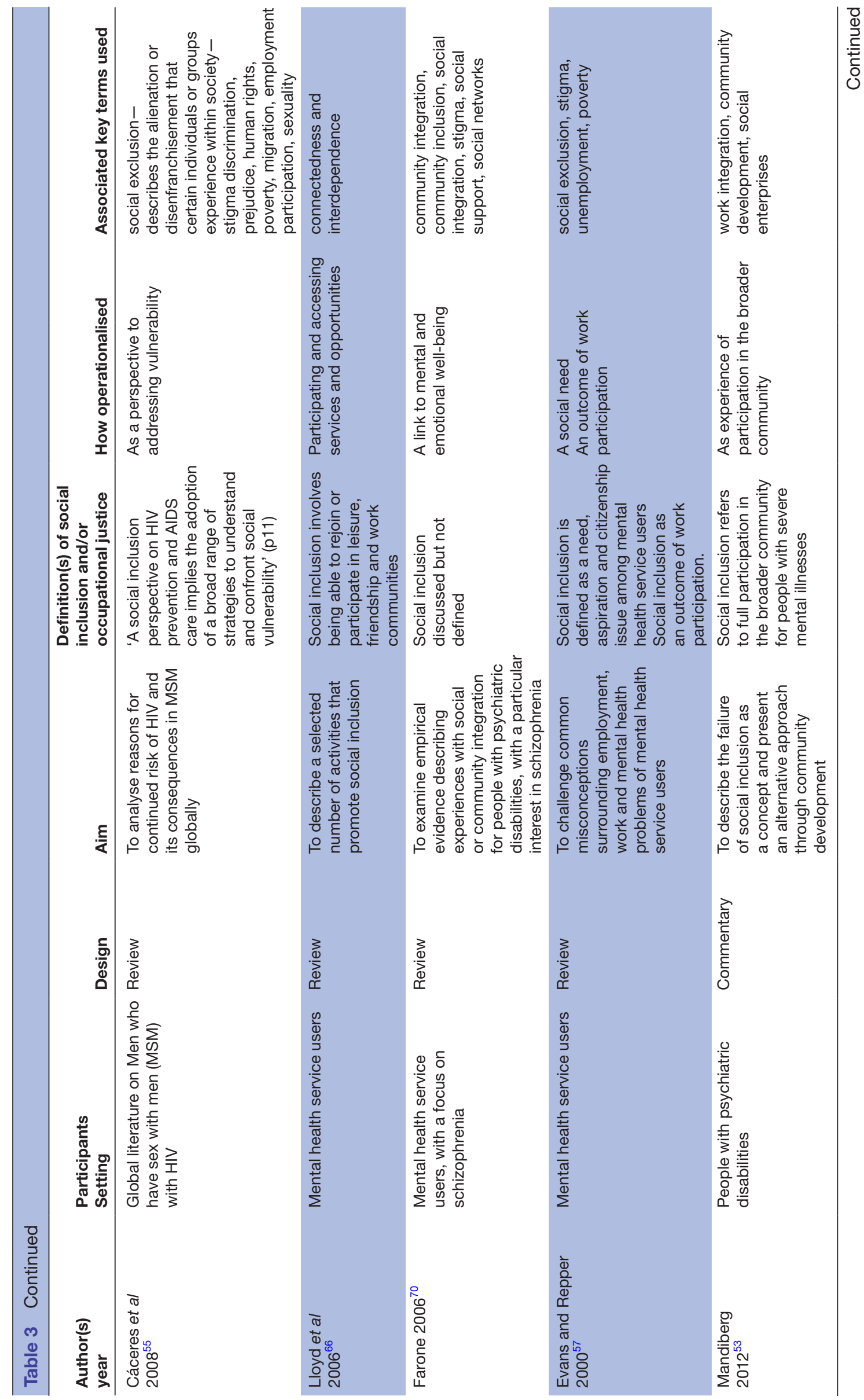




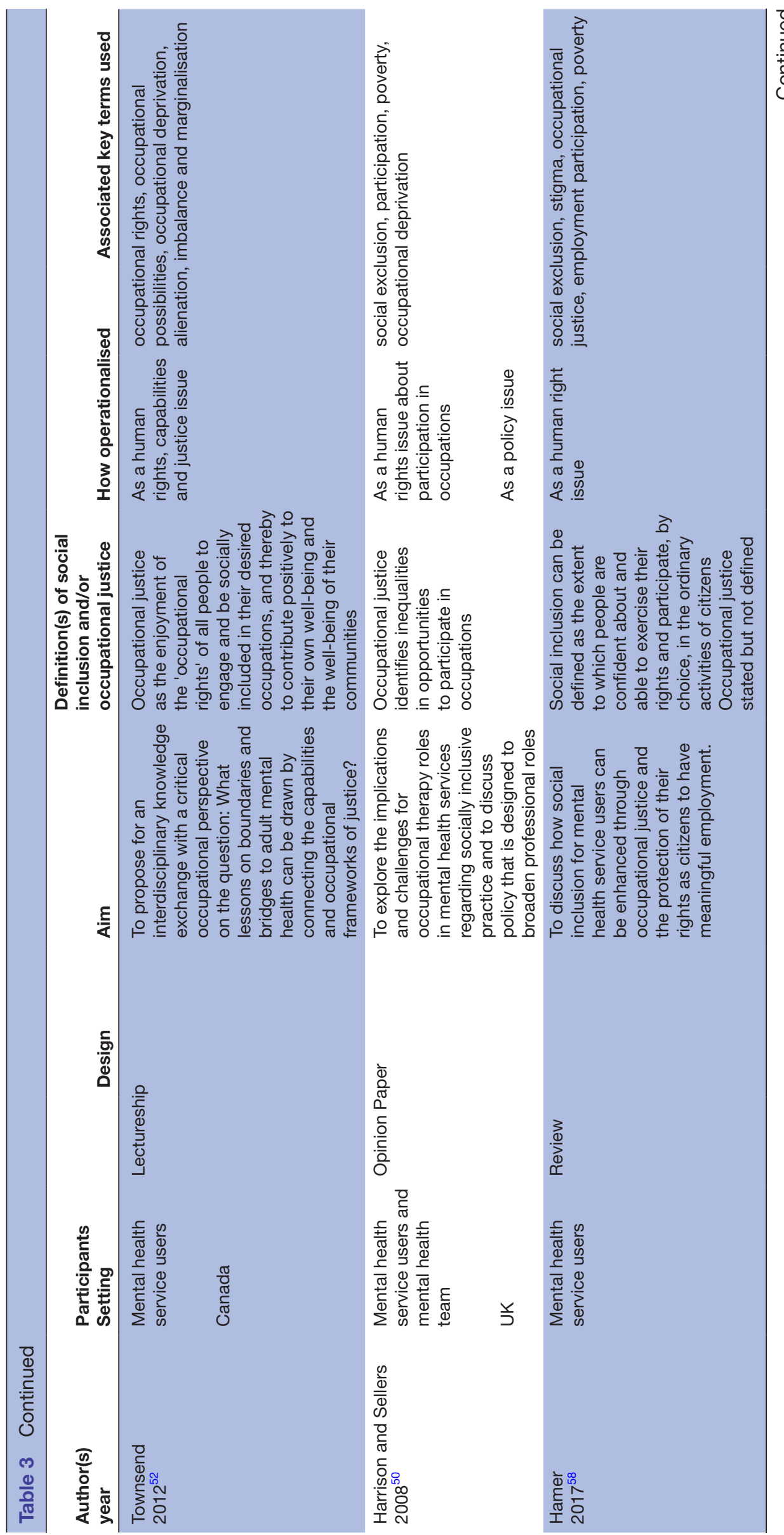




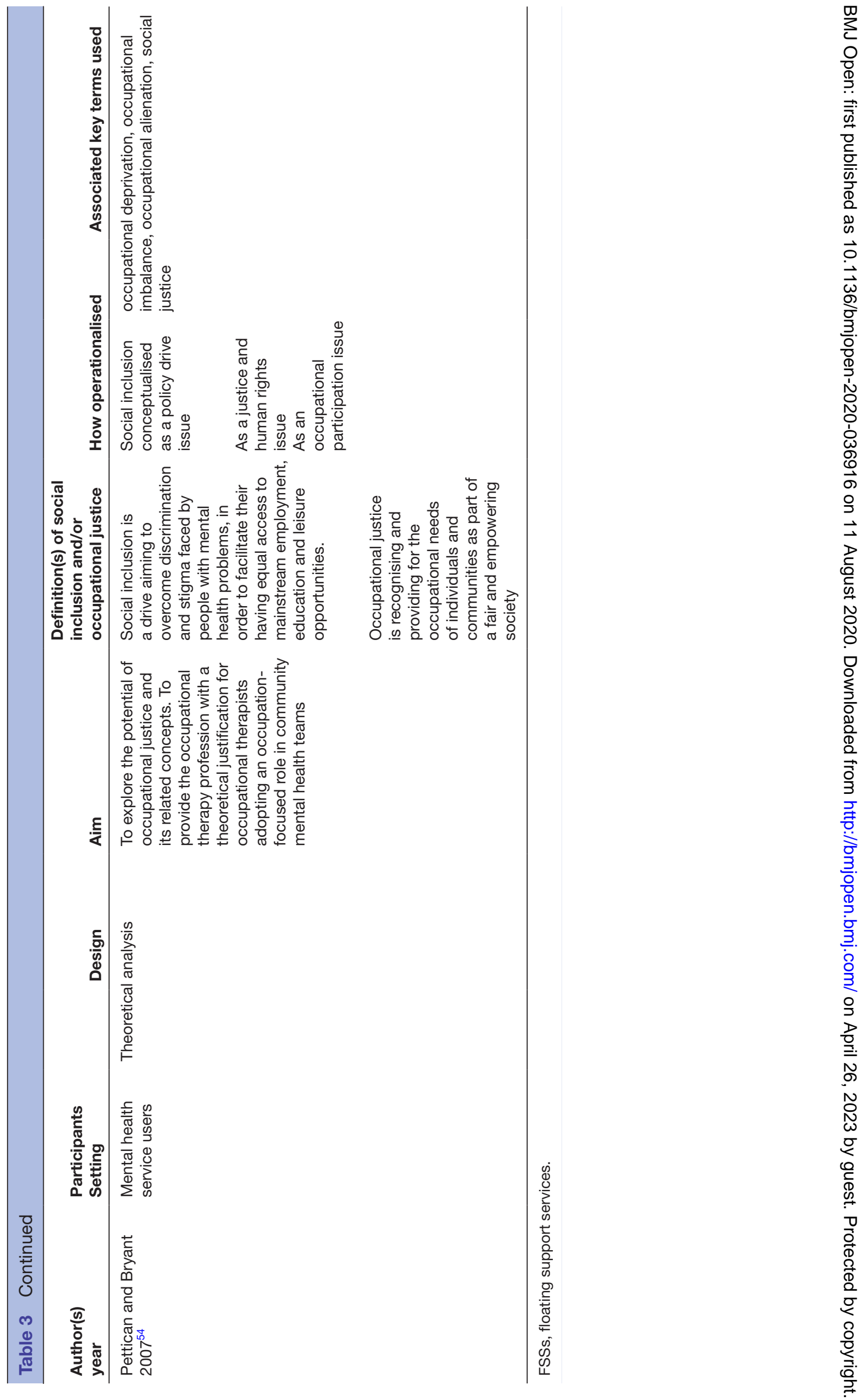


for human rights and healthy social relations and wellbeing are promoted.

\section{CONCEPTUALISING AND DEFINING OCCUPATIONAL JUSTICE}

In the last two decades, only six research papers on mental illness used the concept of occupational justice and provided a definition ${ }^{35} 3646505254$ (table 3). Five different definitions were found (table 3). As with social inclusion, occupational justice was defined with great variability, with it being referred to as both a process and as an experience. ${ }^{35} 3646505254$ Two major themes emerged pointing to social justice in which occupational justice was framed as an occupational rights issue and as a matter of community participation.

\section{Occupational rights}

A key concept of occupational justice for individuals with mental illness was experiencing or enjoying one's occupational rights. ${ }^{35} 3646505254$ Occupational rights were taken to mean an individual's rights to participate in a range of meaningful and contextual occupations enabling them to flourish, fulfil their potential and experience life satisfaction in ways consistent with their contexts. Townsend defined occupational justice as the enjoyment of 'occupational rights' by all people to engage in occupations and feel socially included in their desired occupations, thereby contributing positively to their own well-being and to that of their communities. ${ }^{52}$ Occupational justice was also highlighted as an advocacy process. where individuals could lobby for the occupational rights and needs of individuals and communities as part of an equitable, inclusive and empowering society. ${ }^{36}$

\section{Community participation}

The process of promoting occupational justice was viewed as related to promoting social inclusion and community participation through advancing participation. ${ }^{46}$ In another paper community participation was emphasised, with occupational justice defined as situations when people are seen as having the opportunity to choose to participate in the community. ${ }^{35}$ The core emphasis in the definitions was the acknowledgement of occupational justice as a means of actioning community participation and social justice..$^{35} 46$

However, in all the definitions there was an overuse of the term 'occupation' which forms part of the term we are working to define. While 'occupation' was framed as purposeful everyday activities people engage in, it carries diverse meanings outside occupational science and occupational therapy. This rendered many of the definitions and arguments cyclical in nature.

\section{COMMONALITIES BETWEEN SOCIAL INCLUSION AND OCCUPATIONAL JUSTICE}

Although not clearly articulated, all the papers which discussed the two concepts together seemed to infer that occupational justice was an important ingredient of social inclusion. ${ }^{35} 364652$ Notwithstanding the considerable variability in definitions and conceptualisations of the two concepts, some commonalities were identified (figure 2). Both social inclusion and occupational justice seek to promote equitable access to opportunities for engagement and to seek for fairness and justice in an individual's community participation. ${ }^{35} 364652$

Hamer et al provided the closest account of the relationship between the concepts positing that social inclusion

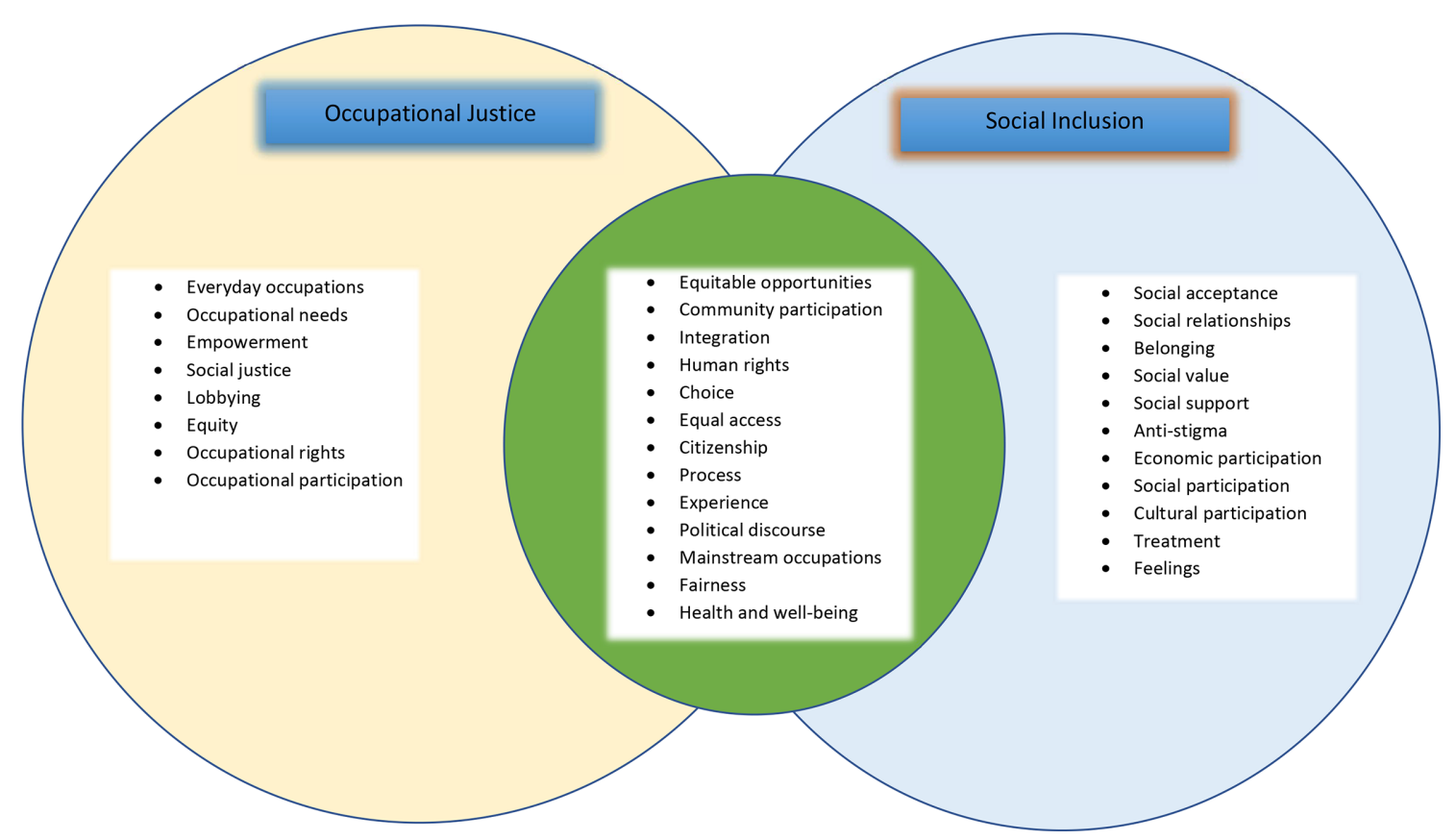

Figure 2 Commonalities between occupational justice and social inclusion definitions-associated terms. 
was enhanced through occupational justice. ${ }^{46}$ Here they argued that recognition of people's right to inclusive participation in everyday occupations (occupational justice) enhanced the extent to which the person became confident about and was able to exercise their rights and participate by choice in the ordinary activities as citizens (social inclusion). ${ }^{46}$ Both concepts were centred on key thematic areas of human rights, equality, inclusivity, and community participation.

Significantly, both social inclusion and occupational justice had a social justice focus, emphasising the right to inclusive participation in a community and individuals exercising choice of participation as part of their citizenry beyond their health conditions. Occupational justice specifies that the participation in meaningful occupations is central, while social inclusion highlights community participation. Both concepts also highlight the need to address discriminatory practices, by doing away with stigma. ${ }^{45} 46$ Hamer and colleagues highlight that social inclusion is the process of experiencing inclusive participation in the community as a citizen, while occupational justice promotes social inclusion through participation in meaningful and valued activities. ${ }^{46}$

\section{DISCUSSION}

We explored and appraised the definitions, current utilisation and relationships between social inclusion and occupational justice in the literature on mental illness and/or HIV. We identified and critically appraised 27 articles that presented a variety of definitions. Although we primarily sought out to describe the conceptualisations and utilisations of these concepts in the duality of mental illness and HIV, we found out that literature is scant and focuses on a single diagnosis. Most studies were on mental illness and conducted in high-income countries. Despite the great variability, key thematic concepts used to define social inclusion and occupational justice included community participation, human rights and relationships. The two concepts are theoretically related through a social justice focus, putting the emphasis on treating people with HIV and those with mental illness in a more respectful and equitable manner. The highlighted thematic concepts are central in directing research and practice toward the moral imperative of addressing exclusions and injustices experienced by people living with HIV, those with mental illnesses and other stigmatised groups. ${ }^{21}$ There is also emphasis on the multidimensional nature of the concepts framed as both a process and a personal experience, also allowing a broader horizon of their application, from policy to practice. The main source of these definitions were qualitative studies using service user's experiences and experts opinions.

While definitions of social inclusion vary, our scoping review findings confirm that the definitions are still in line with the concept of poverty reduction and a focus on reducing stigma and discrimination. ${ }^{44} 4555$ Social inclusion emerged from European societies, in response to a welfare crisis and desire to fight disadvantage.$^{59}$ We propose that this focus on welfare and fighting disadvantage should remain and should be taken up in the mental health and HIV fields, with poverty reduction, justice and equality as pillars of social inclusion. This would be even more effective if poverty reduction was prioritised as a specific focus of social inclusion when informing mental health and HIV policies, particularly in sub-Saharan Africa, where these problems are more prevalent and driven by poverty. ${ }^{3}$

The most striking observation was the lack of clarity in the definition of social inclusion, which is still evident, despite its existence in the literature for almost five decades. ${ }^{59}$ Efforts to be all inclusive, multidimensional, person-centred and contextual can explain the variations and, thus, ambiguity in the definitions. ${ }^{59}{ }^{60}$ However, this lack of definitional clarity could hamper its universal concept utilisation, measurement and further exploration with a common goal. ${ }^{61}{ }^{62}$ This lack of a single, universal understanding has positive and negative implications for research and application of the concept in clinical practice. Without a universally agreed on definition, comparisons between studies and practice remains difficult. ${ }^{62}$ This was echoed in the variety of social inclusion measures applied in the quantitative studies. ${ }^{33} 384345$ Given the variation in measures, a common understanding of what constitutes social inclusion in mental health has not been developed, despite calls for this in recent literature. ${ }^{61-63}$ Therefore construct validity of measures is difficult to test. For the meantime, measures with a broader scope and cross-cultural validation like the Social and Community Opportunities Profile, ${ }^{6465}$ can be instrumental in developing standardised measures.

In contrast, the variations in defining the concepts reflect diversity and the importance of contexts, rather than a singular adoption of a 'universal' idea. Given the diversities in experiences of mental illness and living with HIV, where different regions have their own social, economic, political, cultural and historical realities influencing mental illness and HIV, conceptualisations of social inclusion may benefit from remaining open to multiple definitions in order to reflect the realities of different regions. It is possible to have multiple, but mutual interpretations that could be understood as complementary or even contesting, in line with contextual realities.

Embracing plural definitions may be especially important in low-income and middle-income countries, where such research needs further growth. ${ }^{59}$ For example different activities purported to enhance social inclusion of people with mental health challenges, like paid employment, have different meanings and impact across regions and would influence how it is conceptualised as part of social inclusion. We found a preference towards paid employment as a key determinant of community participation in social inclusion among people with mental health challenges. ${ }^{4047495766}$ This can show the dominant knowledge systems of capitalism in societies ${ }^{59}$ where most of the studies were conducted. Other communal ways of engagement outside of a neo-liberal market structure could be explored as they may facilitate 
new ways of understanding inclusion in the context of HIV and mental illness. In regions where HIV and mental illness are prevalent and complex health and social care problems, we advocate for exploration of social inclusion to generate contextual knowledge, that would inform socially inclusive policies, practice and further research.

Some of the social inclusion definitions had an individual focus, for example the individual had to be actively participating at the expense of the collective found in communal societies. ${ }^{38} 3943$ Given that the studies were mainly from high-income regions, there remains some missing voices in informing the definitions, given the largely communal orientation found in indigenous communities in lowincome and middle-income settings. The challenge in some of the reviewed definitions was to try to focus on the individual and the impact of HIV and/or mental illness, yet the social justice agenda may better be approached from a population level with a focus on broader social determinants of health which has been the case in many countries addressing developmental and intellectual disabilities. ${ }^{67}$ Defining social inclusion of people with mental ill health and HIV also needs to be done from the perspective of people who are in low-income countries, experiencing poverty, unemployment, social inequality and forms of violence, since people with these conditions are usually stigmatised. Discrimination and consequent social problems usually affect people as part of a collective rather than only as individuals. Hence a collective perspective that considers how groups of people are affected can strengthen the concept of social inclusion and promote its possible utility in low-resource practice contexts.

Though the concept of occupational justice has been present in the literature for about three decades, ${ }^{32}$ we found limited evidence of its conceptualisation and application in mental health and no studies in HIV. ${ }^{35} 3646505254$ Despite the global justice theoretical orientation of the concept, the studies found were also exclusively from high-income countries,. ${ }^{35} 3646$ We found key features that could guide occupational justice utilisation and further theorisation in HIV and mental health: community participation by having one's occupational rights upheld, occupational needs met, empowerment and equity in occupational participation. To some extent, the lack of diversity in regions informing the concept offers an opportunity to strengthen it by adding insights from regional contexts with potential for different realities, experiences and viewpoints, such as Africa where HIV and mental illness are prevalent and intertwined. ${ }^{68}$ Also some authors conceptualised occupational justice as participation in occupation(s) in an equitable manner, ${ }^{46}$ they took participation as synonymous with justice, without spelling out the nature of the occupation and position of the person accessing the occupations. These have great potential in influencing how the accessed occupation impacts health, well-being and feeling of social inclusion among those with HIV and mental illnesses.

Despite the definitional lack of clarity, social inclusion and occupational justice are related concepts that can be used together to frame research and practice and inform policy in HIV and mental health. The commonality between the concepts is the need to promote equitable access to opportunities for community participation with fairness and equity for people with HIV and those suffering from mental illness. ${ }^{35} 364652$ The relationship between the concepts could be further developed using diverse communities to build evidence on how engagement in meaningful everyday activities underlie inclusive communities for people with mental illness and those living with HIV. This focus on occupational justice perspective presents an opportunity to routinely explore the nuances of everyday occupational participation and what that may mean for the process and experiences of social inclusion of those involved.

We therefore propose an expansion of the relationship between the conceptualisation of the two concepts, using most affected population groups, such as people with comorbid mental health disorders like substance use disorders and HIV in low-income contexts. This population group is known to have unmet broader health and social care needs hinged to the double stigma associated with substance abuse and HIV. ${ }^{69}$ That expansion should reflect the contextual realities influencing community participation, respect of human rights and having healthy relationships, actioned through engagement in meaningful occupations. These contextually refined concepts of social inclusion and occupational justice should then be used together to inform policy, research and practice, for a just and inclusive society for those with stigmatised conditions like HIV and mental illnesses. The occupational justice and socially inclusive approach from policy through to practice will ensure health and social well-being outcomes are addressed beyond the medical management of mental illness and/or HIV. Health-related quality of life as a holistic construct for promoting continuum of care and health and well-being beyond viral suppression in $\mathrm{HIV}^{22}{ }^{23}$ will also be made practical with a social justice lens.

\section{CONCLUSION}

To our knowledge, this scoping review is the first to appraise the concepts of occupational justice and social inclusion in populations afflicted by mental illness and HIV. Our findings have the potential to initiate critical conversations in the field and expand understanding and utilisation of occupational justice and social inclusion to critique and enhance global mental health. We have also presented commonalities which will give us a better theoretical foundation to inform further research, practice and training, especially from under-represented societies.

\section{Author affiliations}

${ }^{1}$ College of Health Sciences, Rehabilitation Department, University of Zimbabwe, Harare, Zimbabwe

${ }^{2}$ Department of Psychiatry, College of Health Sciences, University of Zimbabwe, African Mental Health Research Initiative (AMARI), Harare, Zimbabwe ${ }^{3}$ Occupational Therapy, Ingutsheni Central Hospital, Bulawayo, Zimbabwe ${ }^{4}$ Florence Nightingale Faculty of Nursing Midwifery and Palliative Care, Cicely Saunders Institute, King's College London, London, UK 
${ }^{5}$ Health and Rehabilitation Sciences, University of Cape Town, Cape Town, South Africa

\section{Twitter Clement Nhunzvi @clemynhu and Richard Harding @RHardingCSI}

Acknowledgements The authors would like to thank Mary Shelton, UCT librarian for assistance in developing our search strategy. This article also benefited from writing soft skills and reviews by Dr Helen Jack through African Mental Health Research Initiative (AMARI).

Contributors All authors have made substantive intellectual contributions to the conduct and write up of this review. CN and RG conceptualised the review approach and provided general guidance to the research team. $\mathrm{CN}$ and EM were involved in systematic and independent screening and data extraction. CN provided primary input at all stages, developed all draft documents and had overall responsibility for the review. LL, RG and RH gave substantial review and critique through the review process and manuscript. All the authors reviewed and commented on the drafts of the manuscript and they all read and approved the final manuscript.

Funding This work was supported through the DELTAS Africa Initiative [DEL-1501]. The DELTAS Africa Initiative is an independent funding scheme of the African Academy of Sciences (AAS) Alliance for Accelerating Excellence in Science in Africa (AESA) and supported by the New Partnership for Africa's Development Planning and Coordinating Agency (NEPAD Agency) with funding from the Wellcome Trust [DEL-15-01] and the UK government.

Disclaimer The views expressed in this publication are those of the author(s) and not necessarily those of AAS, NEPAD Agency, Wellcome Trust or the UK government.

Competing interests None.

Patient consent for publication Not required.

Provenance and peer review Not commissioned; externally peer reviewed.

Data availability statement № additional data available.

Open access This is an open access article distributed in accordance with the Creative Commons Attribution 4.0 Unported (CC BY 4.0) license, which permits others to copy, redistribute, remix, transform and build upon this work for any purpose, provided the original work is properly cited, a link to the licence is given, and indication of whether changes were made. See: https://creativecommons.org/ licenses/by/4.0/.

ORCID iDs

Clement Nhunzvi http://orcid.org/0000-0001-5804-9817

Richard Harding http://orcid.org/0000-0001-9653-8689

\section{REFERENCES}

1 UNAIDS. UNAIDS data. Geneva, 2019.

2 Pandey A, Galvani AP. The global burden of HIV and prospects for control. The Lancet HIV 2019;6:e809-11.

3 UNAIDS. Global AIDS update 2019 - communities at the centre - defending rights, breaking barriers, reaching people with HIV services. Geneva, 2019.

4 Bauer-Staeb C, Jörgensen L, Lewis G, et al. Prevalence and risk factors for HIV, hepatitis $B$, and hepatitis $C$ in people with severe mental illness: a total population study of Sweden. Lancet Psychiatry 2017;4:685-93.

5 Hughes E, Bassi S, Gilbody S, et al. Prevalence of HIV, hepatitis B, and hepatitis $C$ in people with severe mental illness: a systematic review and meta-analysis. Lancet Psychiatry 2016;3:40-8.

6 Patel P, Rose CE, Collins PY, et al. Noncommunicable diseases among HIV-infected persons in low-income and middleincome countries: a systematic review and meta-analysis. AIDS 2018;32(Suppl 1):S5.

7 Bhatia R, Hartman C, Kallen MA, et al. Persons newly diagnosed with HIV infection are at high risk for depression and poor linkage to care: results from the steps study. AIDS Behav 2011:15:1161-70.

8 Mayston R, Kinyanda E, Chishinga N, et al. Mental disorder and the outcome of HIV/AIDS in low-income and middle-income countries: a systematic review. AIDS 2012;26(Suppl 2):S117-35.

9 Nyongesa MK, Mwangala PN, Mwangi P, et al. Neurocognitive and mental health outcomes and association with quality of life among adults living with HIV: a cross-sectional focus on a low-literacy population from coastal Kenya. BMJ Open 2018;8:e023914.

10 Lowther K, Selman L, Harding R, et al. Experience of persistent psychological symptoms and perceived stigma among people with
HIV on antiretroviral therapy (ART): a systematic review. Int $J$ Nurs Stud 2014:51:1171-89.

11 Sin NL, DiMatteo MR. Depression treatment enhances adherence to antiretroviral therapy: a meta-analysis. Ann Behav Med 2014;47:259-69.

12 UNAIDS. Thematic segment: mental health and HIVIAIDS promoting human rights, an integrated and person-centred approach to improving art adherence, well-being and quality of life. Geneva, 2018.

13 Jackson-Best F, Edwards N. Stigma and intersectionality: a systematic review of systematic reviews across HIV/AIDS, mental illness, and physical disability. BMC Public Health 2018;18:919.

14 Aidala AA, Wilson MG, Shubert V, et al. Housing status, medical care, and health outcomes among people living with HIV/AIDS: a systematic review. Am J Public Health 2016;106:e1-23.

15 Breuer E, Myer L, Struthers H, et al. HIV/AIDS and mental health research in sub-Saharan Africa: a systematic review. Afr J AIDS Res 2011:10:101-22.

16 Levi-Minzi MA, Surratt HL. HIV stigma among substance abusing people living with HIV/AIDS: implications for HIV treatment. AIDS Patient Care STDS 2014;28:442-51.

17 Durocher E, Rappolt S, Gibson BE. Occupational justice: future directions. J Occup Sci 2013;21.

18 Nilsson I, Townsend E. Occupational Justice-Bridging theory and practice. Scand J Occup Ther 2010;17:57-63.

19 Cobigo V, Stuart H. Social inclusion and mental health. Curr Opin Psychiatry 2010;23:453-7.

20 Pereira RB, Whiteford GE. Understanding social inclusion as an international discourse: implications for enabling participation. $\mathrm{Br} \mathrm{J}$ Occup Ther 2013;76:112-5.

21 Nilsson I, Townsend E. Occupational justice-bridging theory and practice. Scand J Occup Ther 2010;17:57-63.

22 Lazarus JV, Safreed-Harmon K, Barton SE, et al. Beyond viral suppression of HIV - the new quality of life frontier. BMC Med 2016;14:94.

23 Kall M, Marcellin F, Harding R, et al. Patient-reported outcomes to enhance person-centred HIV care. The Lancet HIV 2020;7:e59-68.

24 Baumgartner JN, Burns JK. Measuring social inclusion--a key outcome in global mental health. Int J Epidemiol 2014;43:354-64.

25 Patel V, Saxena S, Frankish H, et al. Sustainable development and global mental health--a Lancet Commission. Lancet 2016;387:1143-5.

26 McKinstry C, Brown T, Gustafsson L. Scoping reviews in occupational therapy: the what, why, and how to. Aust Occup Ther $J$ 2014;61:58-66.

27 Nhunzvi C, Langhaug L, Mavindidze E, et al. Occupational justice and social inclusion in mental illness and HIV: a scoping review protocol. BMJ Open 2019;9:e024049.

28 Grant MJ, Booth A. A typology of reviews: an analysis of 14 review types and associated methodologies. Health Info Libr J 2009;26:91-108.

29 Arksey H, O'Malley L. Scoping studies: towards a methodological framework. Int J Soc Res Methodol 2005;8:19-32.

30 Halas G, Schultz ASH, Rothney J, et al. A scoping review protocol to map the research foci trends in tobacco control over the last decade. BMJ Open 2015;5:e006643.

31 Tricco AC, Lillie E, Zarin W, et al. PRISMA extension for scoping reviews (PRISMA-ScR): checklist and explanation. Ann Intern Med 2018:169:467-73.

32 Serrata Malfitano AP, Gomes da Mota de Souza R, Esquerdo Lopes R. Occupational justice and its related concepts: an historical and thematic scoping review. OTJR 2016;36:167-78.

33 Berry C, Greenwood K. Direct and indirect associations between dysfunctional attitudes, self-stigma, hopefulness and social inclusion in young people experiencing psychosis. Schizophr Res 2018;193:197-203.

34 Clewes J, Shivamurthy S, Wrigley S. Brightening his days: a reflective single case-study of social integration and recovery. Occupational Therapy in Mental Health 2013;29:159-80.

35 Farrell C, Bryant W. Voluntary work for adults with mental health problems: an exploration of the perspectives of recruiters. British Journal of Occupational Therapy 2009;72:188-96.

36 Fieldhouse J. Community participation and recovery for mental health service users: an action research inquiry. Br J Occup Ther2012;75:419-28.

37 Fieldhouse J. Mental health, social inclusion, and community development: lessons from Bristol. Community Dev J 2012;47:571-87.

38 Killaspy $\mathrm{H}$, White $\mathrm{S}$, Lalvani $\mathrm{N}$, et al. The impact of psychosis on social inclusion and associated factors. Int J Soc Psychiatry 2014:60:148-54. 
39 Mazzi F, Baccari F, Mungai F, et al. Effectiveness of a social inclusion program in people with non-affective psychosis. BMC Psychiatry 2018;18:179.

40 Nieminen I, Ramon S, Dawson I, et al. Experiences of social inclusion and employment of mental health service users in a European Union project. Int J Ment Health 2012;41:3-23.

41 Raitakari S, Haahtela R, Juhila K. Tackling community integration in mental health home visit integration in Finland. Health Soc Care Community 2016;24:e53-62.

42 Ramon S, Griffiths CA, Nieminen I, et al. Towards social inclusion through lifelong learning in mental health: analysis of change in the lives of the EMILIA project service users. Int J Soc Psychiatry 2011;57:211-23.

43 Saavedra J, Pérez E, Crawford P, et al. Recovery and creative practices in people with severe mental illness: evaluating well-being and social inclusion. Disabil Rehabil 2018;40:905-11.

44 Smyth G, Harries P, Dorer G. Exploring mental health service users' experiences of social inclusion in their community occupations. $\mathrm{Br} \mathrm{J}$ Occup Ther2011;74:323-31.

45 Turner N, Ferguson L, Hill M, et al. An exploratory study of the extent of social inclusion among people with psychosis and psychoticrelated conditions. Int J Soc Psychiatry 2017;63:195-202.

46 Hamer HP, Kidd J, Clarke S, et al. Citizens un-interrupted: practices of inclusion by mental health service users. Journal of Occupational Science 2017;24:76-87.

47 Stain HJ, Galletly CA, Clark S, et al. Understanding the social costs of psychosis: the experience of adults affected by psychosis identified within the second Australian national survey of psychosis. Aust N Z J Psychiatry 2012;46:879-89.

48 Moraes Salles M, Sn B. The social EXCLUSION/INCLUSION of users of a psychosocial care center in everyday life. Texto \& Contexto Enfermagem 2013;22:704-12.

49 Salles MM, Barros S. Social representation of users of a psychosocial care center and those in their social network on mental illness and social inclusion. Saude E Sociedade 2013;22:1059-71.

50 Harrison D, Sellers A. Occupation for mental health and social inclusion. Br J Occup Ther2008;71:216-9.

51 Le Boutillier C, Croucher A. Social inclusion and mental health. Br J Occup Ther2010;73:136-9.

52 Townsend EA. Boundaries and bridges to adult mental health: critical occupational and capabilities perspectives of justice. J Occup Sci 2012;19:8-24.

53 Mandiberg JM. Commentary: the failure of social inclusion: an alternative approach through community development. Psychiatr Serv 2012;63:458-60.
54 Pettican A, Bryant W. Sustaining a focus on occupation in community mental health practice. British Journal of Occupational Therapy 2007;70:140-6.

55 Cáceres CF, Aggleton P, Galea JT. Sexual diversity, social inclusion and HIV/AIDS AIDS 2008;22:S45-55.

56 Cobigo V, Stuart H. Social inclusion and mental health. Curr Opin Psychiatry 2010;23:453-7.

57 Evans J, Repper J. Employment, social inclusion and mental health. J Psychiatr Ment Health Nurs 2000;7:15-24.

58 Hamer H. Returning citizens: social inclusion and occupational justice for mental health service users. Cadernos Brasileiros de Saúde Mental/Brazilian Journal of Mental Health 2017;9:89-113.

59 Rawal N. Social inclusion and exclusion: a review. Dhaulagiri Journal of Sociology and Anthropology 2008;2:161-80.

60 Silver $\mathrm{H}$. The contexts of social inclusion 2015

61 Baumgartner JN, Burns JK. Measuring social inclusion--a key outcome in global mental health. Int J Epidemiol 2014;43:354-64.

62 O'Donnell P, O'Donovan D, Elmusharaf K. Measuring social exclusion in healthcare settings: a scoping review. Int $J$ Equity Health 2018;17:15.

63 Huxley P, Thornicroft G. Social inclusion, social quality and mental illness. Br J Psychiatry 2003;182:289-90.

64 Huxley PJ, Chan K, Chiu M, et al. The social and community opportunities profile social inclusion measure: structural equivalence and differential item functioning in community mental health residents in Hong Kong and the United Kingdom. Int J Soc Psychiatry 2016;62:133-40.

65 Chan K, Evans S, Ng Y-L, et al. A concept mapping study on social inclusion in Hong Kong. Soc Indic Res 2014;119:121-37.

66 Lloyd C, Tse S, Deane FP. Community participation and socia inclusion: how practitioners can make a difference. Aust e-J Adv Mental Health 2006;5:185-94.

67 Martin L, Cobigo V. Definitions matter in understanding social inclusion. J Policy Pract Intellect Disabil 2011;8:276-82.

68 Brandt R. The mental health of people living with HIV/AIDS in Africa: a systematic review. Afr J AIDS Res 2009;8:123-33.

69 Duffy M, Sharer M, Cornman $\mathrm{H}$, et al. Integrating mental health and HIV services in Zimbabwean communities: a nurse and Communityled approach to reach the most vulnerable. J Assoc Nurse AIDS C2015:1-13.

70 Farone DW. Schizophrenia, community integration, and recovery implications for social work practice. Social Work in Mental Health 2006;4:21-36. 